\title{
Correction to: Increase of magnetic hyperthermia efficiency due to optimal size of particles: theoretical and experimental results
}

\author{
L. H. Nguyen • V. T. K. Oanh • P. H. Nam • \\ D. H. Doan • N. X. Truong • N. X. Ca • P. T. Phong • \\ L. V. Hong • T. D. Lam
}

Published online: 22 March 2021

(C) Springer Nature B.V. 2021

\section{Correction to: J Nanopart Res (2020) 22: 258 https://doi.org/10.1007/s11051-020- 04986-5}

The original version of this article unfortunately contained a mistake: First, typo mistake on the address of the co-authors which is "Faculty of Applied Science" to "Faculty of Applied Sciences," and second, the value of SARs (LRT, exp) are $26.81 \mathrm{~W} / \mathrm{g}$ and $30.38 \mathrm{~W} / \mathrm{g}$ for L1 and L2 (Table 5 and Fig. 9), respectively. The correct

The online version of the original article can be found at https://doi. org/10.1007/s11051-020-04986-5

L. H. Nguyen · P. T. Phong

Laboratory of Magnetism and Magnetic Materials, Advanced Institute of Materials Science, Ton Duc Thang University, Ho Chi Minh City, Vietnam

\section{H. Nguyen}

e-mail: luuhuunguyen@tdtu.edu.vn

L. H. Nguyen · P. T. Phong

Faculty of Applied Sciences, Ton Duc Thang University, Ho Chi Minh City, Vietnam

V. T. K. Oanh $(\bowtie) \cdot$ P. H. Nam • D. H. Doan $\cdot$

N. X. Truong $\cdot$ L. V. Hong

Institute of Materials Science, Vietnam Academy of Science and Technology, 18- Hoang Quoc Viet Road, Hanoi, Vietnam ones are $30.31 \mathrm{~W} / \mathrm{g}$ and $34.48 \mathrm{~W} / \mathrm{g}$ for $\mathrm{L} 1$ and $\mathrm{L} 2$, respectively.

The corrected information is shown below:

1. Faculty of Applied Sciences.

e-mail: oanhvtk@ims.vast.ac.vn

\section{T. K. Oanh}

Graduate University of Science and Technology, 18- Hoang Quoc Viet Street, Cau Giay District, Hanoi, Vietnam

N. X. Ca

Department of Physics and Technology, TNU - University of Science, Thai Nguyen City, Vietnam

\section{T. D. Lam}

Institute for Tropical Technology, Vietnam Academy of Science and Technology, 18 Hoang Quoc Viet Road, Hanoi, Vietnam 
Table 5 The value of $S A R_{\text {exp }}, S A R_{\text {exp }}^{\text {hys }}, S A R_{\text {exp }}^{L R T}$ of the $\mathrm{Fe}_{3} \mathrm{O}_{4} \mathrm{MNPs}$ and $S A R_{\text {theo }}^{L R T}$ with various standard deviation

\begin{tabular}{|c|c|c|c|c|c|c|c|}
\hline \multirow[t]{3}{*}{ Sample } & \multirow[t]{3}{*}{ Size nanoparticles $(\mathrm{nm})$} & \multirow[t]{3}{*}{$S A R_{\exp }(\mathrm{W} / \mathrm{g})$} & \multirow[t]{3}{*}{$S A R_{\text {exp }}^{h y s}(\mathrm{~W} / \mathrm{g})$} & \multirow[t]{3}{*}{$S A R_{\exp }^{L R T}(\mathrm{~W} / \mathrm{g})$} & \multicolumn{3}{|l|}{$S A R_{\text {theo }}^{L R T}(\mathrm{~W} / \mathrm{g})$} \\
\hline & & & & & \multirow{2}{*}{$\begin{array}{l}\text { Monodisperse } \\
\sigma=0\end{array}$} & \multicolumn{2}{|c|}{ Polydisperse } \\
\hline & & & & & & $\sigma=0.2$ & $\sigma=0.4$ \\
\hline L1 & 5 & 30.31 & 0 & 30.31 & 0.3 & 0.5 & 6.8 \\
\hline $\mathrm{L} 2$ & 10 & 34.48 & 0 & 34.48 & 2.6 & 32.8 & 68.9 \\
\hline L3 & 12 & 48.07 & 10.45 & 37.62 & 7.5 & 81.9 & 96.2 \\
\hline L4 & 15 & 64.79 & 10.81 & 53.98 & 60.1 & 162.9 & 123.6 \\
\hline L5 & 20 & 123.31 & 10.82 & 112.49 & 305.1 & 195.6 & 132.3 \\
\hline
\end{tabular}

Fig. $9 \mathrm{SAR}_{\text {exp }}$ versus $D$ of $\mathrm{Fe}_{3} \mathrm{O}_{4}$ MNPS

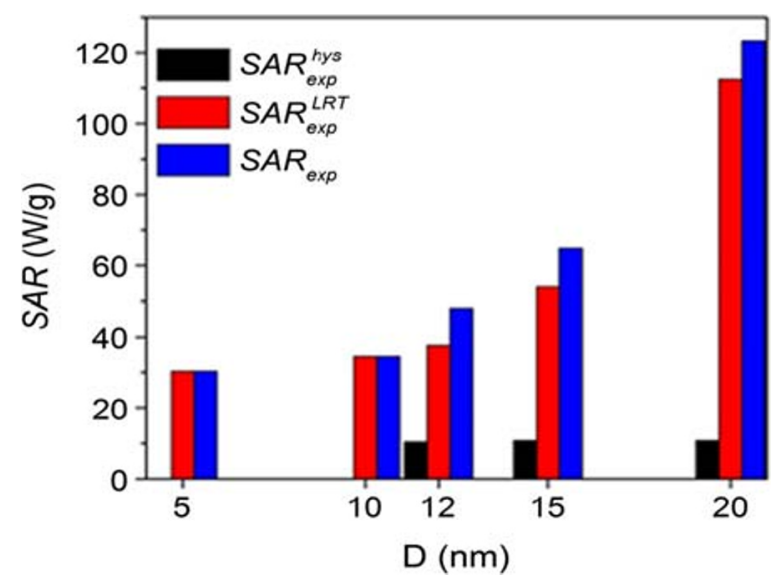

Publisher's note Springer Nature remains neutral with regard to jurisdictional claims in published maps and institutional affiliations.

Fig. $9 S A R_{\text {exp }}$ versus $D$ of $\mathrm{Fe}_{3} \mathrm{O}_{4}$ MNPS 